\title{
Serotonin Depletion Impairs Waiting but not Stop-Signal Reaction Time in Rats: Implications for Theories of the Role of $5-\mathrm{HT}$ in Behavioral Inhibition
}

\author{
Dawn M Eagle*,', Olivia Lehmann', David EH Theobald', Yolanda Pena', Rasheed Zakaria', Rhia Ghosh', \\ Jeffrey W Dalley ${ }^{1,2}$ and Trevor W Robbins' \\ 'Department of Experimental Psychology and the Behavioural and Clinical Neuroscience Institute, University of Cambridge, Cambridge, UK; \\ ${ }^{2}$ Department of Psychiatry, Addenbrooke's Hospital, University of Cambridge, Cambridge, UK
}

\begin{abstract}
Central serotonin (5-HT) function is thought to be a critical component of behavioral inhibition and impulse control. However, in recent clinical studies, 5-HT manipulations failed to affect stop-signal reaction time (SSRT), which is a fundamental process in behavioral inhibition. We investigated the effect of central 5-HT depletion (intracerebroventricular 5,7-dihydroxytryptamine) in rats on two aspects of behavioral inhibition, SSRT and 'waiting', using the stop-signal task. 5-HT depletion had no effects on SSRT or any other primary measure on the stop-signal task. However, within the same task, there was a deficit in 'waiting' in 5-HT-depleted rats when they were required to withhold from responding in the terminal element of the stop-signal task for an extended period. D-Amphetamine had dosedependent, but not 5-HT-dependent effects on SSRT. Conversely, the dose that tended to improve, or decrease, SSRT (0.3 mg/kg) impaired the ability to wait, again independently of 5-HT manipulation. These findings suggest that SSRT and 'waiting' are distinct measures of behavioral inhibition, and show that $5-\mathrm{HT}$ is critical for some forms of behavioral inhibition but not others. This has significant implications for the treatment of conditions such as attention deficit and hyperactivity disorder, substance abuse, and affective disorders, in which inhibitory and impulse-control deficits are common.

Neuropsychopharmacology (2009) 34, I31 I-1321; doi:I0.1038/npp.2008.202; published online 12 November 2008
\end{abstract}

Keywords: impulsivity; inhibition; 5-HT; ADHD; OCD

\section{INTRODUCTION}

Central serotonin (5-HT) function is an important component of normal behavioral inhibition that controls impulsive responding (Evenden, 1999; Linnoila et al, 1983; Soubrié, 1986; Winstanley et al, 2006). Pathological levels of inhibition failure and impulsivity are common to psychiatric conditions such as attention deficit and hyperactivity disorder (ADHD) (Aron and Poldrack, 2005; Oosterlaan et al, 1998; Rubia et al, 2007; Schachar et al, 1995), Parkinson's disease (Gauggel et al, 2004; van den Wildenberg et al, 2006), schizophrenia (Bellgrove et al, 2006), obsessive-compulsive disorder (Chamberlain et al, 2005; Penades et al, 2007), and chronic drug abuse (eg cocaine (Fillmore and Rush, 2002), amphetamine (de Wit et al, 2000), and methamphetamine (Monterosso et al, 2005)).

*Correspondence: Dr DM Eagle, Department of Experimental Psychology, Behavioural and Clinical Neuroscience Institute, University of Cambridge, Downing Site, Cambridge CB2 3EB, UK,

Tel: + 441223 333550, Fax: + 441223333564 ,

E-mail: del02@cam.ac.uk

Received 10 July 2008; revised 29 September 2008; accepted 6 October 2008
Thus, abnormal 5-HT function may be central to the development of these conditions.

Behavioral inhibition may have many elements, modulated by different brain regions or neurotransmitters (Dalley et al, 2008; Eagle et al, 2008; Pattij and Vanderschuren, 2008). One commonly defined component, impulsive action', embraces any behavior in which the ability to inhibit actions is impaired. The dichotomy of 'impulsive action' and 'impulsive choice' is used to define models of impulse control that are central to the clinical assessment of ADHD in particular (Dalen et al, 2004; Sonuga-Barke, 2003).

There are numerous behavioral tests of impulsive action that are considered to be directly comparable with one another, such as the continuous performance task (CPT) and its analogues in rat studies, the 5-choice serial reaction time (5-CSRT) task, differential reinforcement of low rates of responding (DRL) tasks, stop-signal tasks, and go/no-go tasks. Indeed, 5-HT function is linked with the modulation of impulsive action on many of these tests. For example, premature response control ('waiting') on the rat 5-CSRT task and human CPT is influenced by 5 -HT receptor manipulations and central 5-HT depletion (Carli et al, 2006; Carli and Samanin, 2000; Dougherty et al, 2007; Harrison 
et al, 1997; Robinson et al, 2007; Walderhaug et al, 2002, 2008). Furthermore, 5-HT depletion also impaired go/no-go inhibition in rats and hostile aggressive children with ADHD (Harrison et al, 1999; Masaki et al, 2006; Zepf et al, 2008).

However, recent studies have consistently failed to find effects of 5-HT manipulations on the speed of the inhibitory process or stop-signal reaction time (SSRT), measured by the stop-signal task. Neither 5-HT depletion nor treatment with citalopram, a selective 5 -HT reuptake inhibitor (SSRI), significantly affected SSRT in healthy human volunteers (Chamberlain et al, 2006; Clark et al, 2005). Furthermore, the absence of effect of citalopram on SSRT was reproduced in rats (Eagle et al, 2008), showing that the failure of 5-HT to influence this form of inhibition translates consistently across species.

If 5-HT manipulations have such different effects on two forms of impulsive action, this brings into question whether impulsive action represents a valid construct within a theory of behavioral inhibition and during clinical assessment of patients with impulse-control disorders. This is highlighted in a recent study that failed to find any significant relationship between CPT and stop-signal-task forms of impulsive action in adolescents (Reynolds et al, 2008).

We investigated the effects of 5-HT depletion on SSRT and 'waiting' components of impulsive action control on the stop-signal task. Rats performed a rapid reaction time task and were required to withhold their response on a small percentage of stop trials following stop-signal presentation. The stop signal could be early or late in the trial, making it more or less possible to inhibit the response. To measure SSRT, stop-signals were presented close to the completion of the go response, requiring the motor response to be stopped well after its execution had begun. SSRT was estimated using a well-defined and -tested mathematical model, the race model (Logan and Cowan, 1984) (see Supplementary Information). To measure the ability to wait, the stop signal was presented at the start of each stop trial, and rats were required to withhold responding for an extended period, in trials comparable to extended ITI tests in the 5-CSRT task (Dalley et al, 2007).

We also describe the effects of the stimulant D-amphetamine on SSRT and 'waiting' using the same task manipulations. Previous studies have shown that D-amphetamine decreased, or improved, long SSRTs in both rat and human studies (de Wit et al, 2000, 2002; Eagle and Robbins, 2003a; Feola et al, 2000), but impaired the ability to wait in the 5-CSRT task, suggesting that these forms of behavior may be mediated through different neurotransmitter mechanisms.

\section{MATERIALS AND METHODS}

\section{Subjects}

Subjects were 24 male Lister-hooded rats (Charles River, UK), housed in groups of four in environmentally enriched cages. Experiments were conducted during the dark phase of a reversed 12-h light-dark cycle (lights off at 0730 hours). Rats weighed $275 \pm 20 \mathrm{~g}$ initially and $410 \pm 30 \mathrm{~g}$ at surgery, with weights maintained at approximately $90 \%$ of free- feeding weight (based on rat growth curves Harlan, UK). During testing, rats were fed 15-20 g of food per day (task reinforcer pellets plus laboratory chow given $1-2 \mathrm{~h}$ after the end of the daily test session), restricting weight gain to $1-2 \mathrm{~g}$ per week. All experiments were conducted in accordance with the United Kingdom Animals (Scientific Procedures) Act, 1986.

\section{Experimental Design}

Rats were trained in six operant-conditioning chambers, each with two retractable levers either side of a central food well (Med Associates, Vermont, USA). The protocol and training have been described in detail previously (Eagle and Robbins, 2003a, b). A houselight in the roof of the chamber was on throughout the session. A pellet dispenser delivered 45-mg Noyes Formula $\mathrm{P}$ pellets (Sandown Scientific, Middlesex, UK) into the food well, and nose entry into the food well was monitored with an infrared detector. A center light, above the food well, signaled reinforcer delivery. Lights above the left and right levers signaled presentation of their respective levers. A $4500-\mathrm{Hz}$ Sonalert tone generator (Med Associates) was mounted high on the wall opposite to the levers and food well. Control of the chambers and online data collection were conducted using the Whisker control system (Cardinal and Aitken, 2001), using the Stop Task program, written by DM Eagle and JMC England. Rats were tested 5 days per week except during drug testing (see schedule below), and performed one 20-min session per day, with a maximum of 200 trials per session.

Each trial began with a nose poke to the central food well, after which the left lever and left light were presented (Figure 1). A left-lever press resulted in presentation of the right lever and the left lever/light was withdrawn/extinguished. Rats responded rapidly between left lever and right lever presses - the 'go' response. Response speed was maintained by limiting the time for which the right lever was available, the limited hold (LH). The LH was set during training at a value that maintained the maximum performance of both fast, accurate go trials, and accurate no-delay stop trials. $\mathrm{LH}$ ranged between 0.9 and $2.65 \mathrm{~s}$ (mean \pm SEM: $1.64 \pm 0.08)$, a constant value for each rat throughout the study. During go trials, rats were rewarded with one pellet for pressing the right lever but received a timeout of $5 \mathrm{~s}$ in darkness if the right lever was not pressed within the $\mathrm{LH}$ period.

A stop-signal tone $(40 \mathrm{~ms}, 4500 \mathrm{~Hz})$ was presented on $20 \%$ of the trials at a predetermined time between the left and right lever presses. Stop trials were randomized within the session to discourage anticipatory slowing of response speed. On 'stop' trials, rats initiated the same response as on go trials but following the stop signal they were required to withhold the right lever press for the duration of the $\mathrm{LH}$ period. A correctly withheld response was rewarded with one pellet and an incorrect stop-trial response (right lever press) gave a 5-s timeout. On a few trials designated as stop trials, the rat responded on the right lever before the stopsignal onset (more common for late tone presentations), and these trials were reclassified as go trials to maintain the overall proportion of valid stop trials in each session at $20 \%$. Rats were trained to stable baseline performance (three consecutive days of greater than $70 \%$ accuracy on 


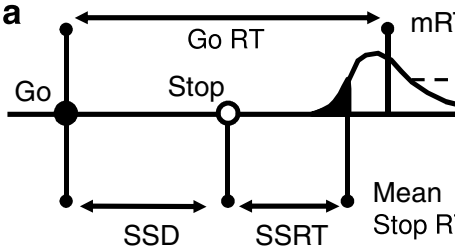

$0 \%$ Stop trials c $80 \%$ Stop trials
stopped correctly

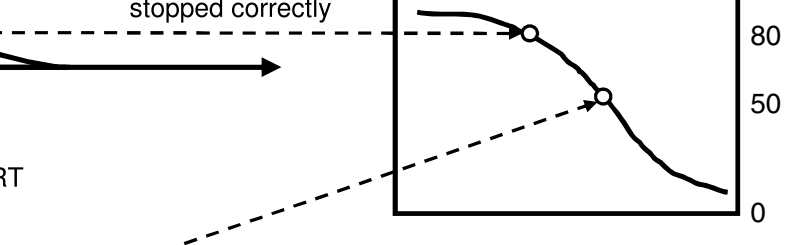

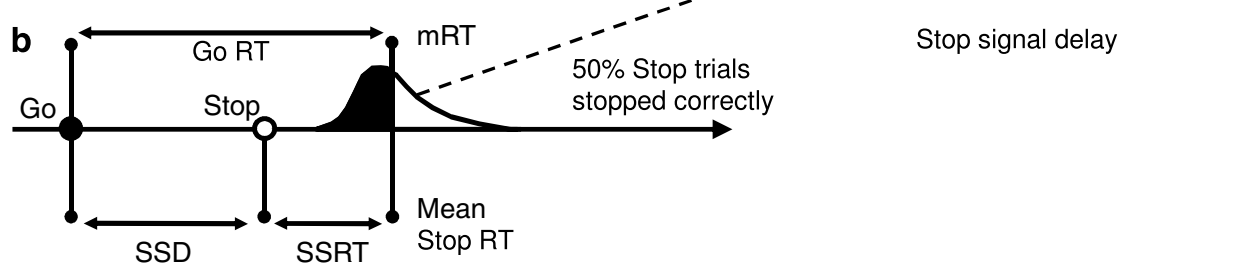
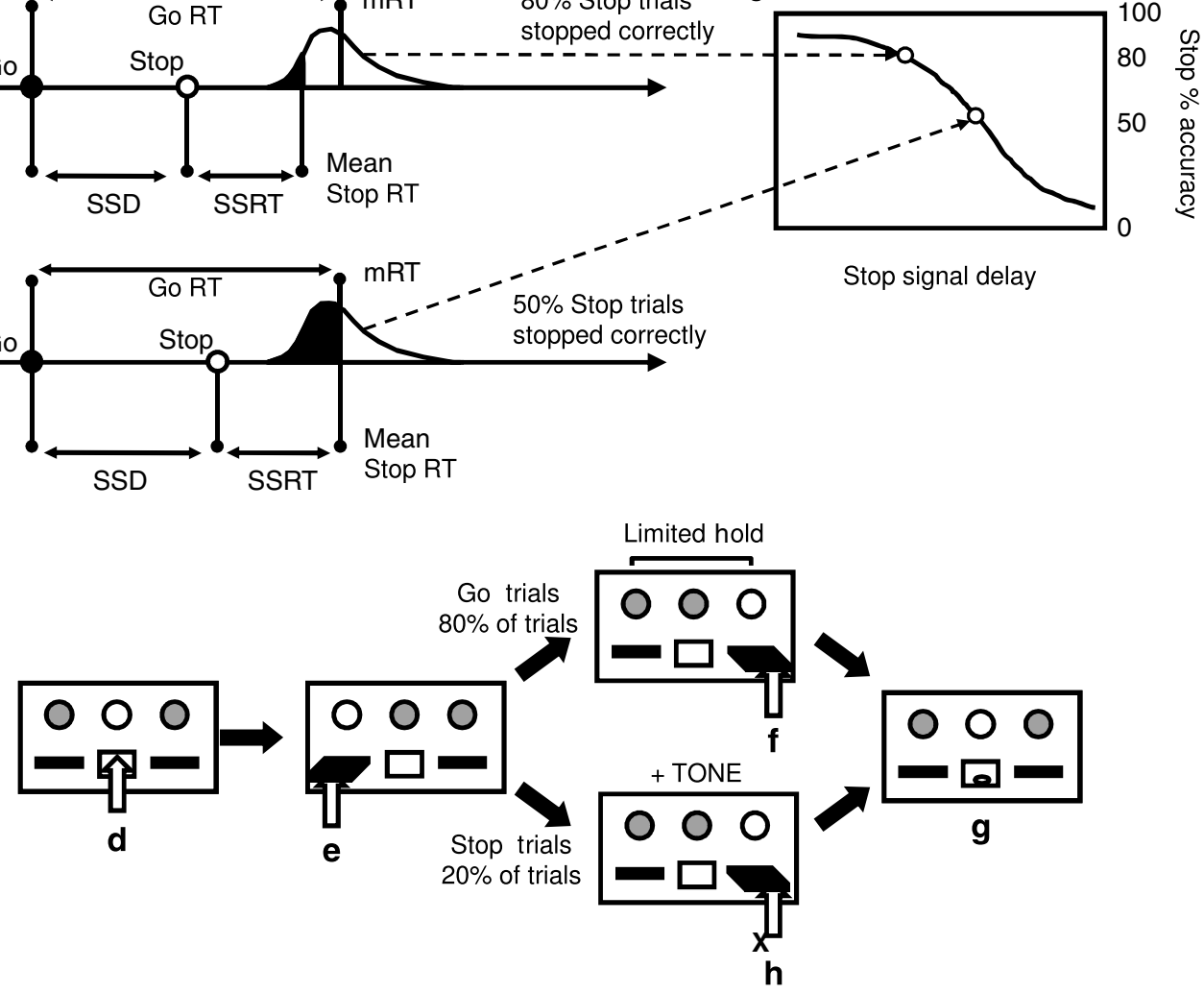

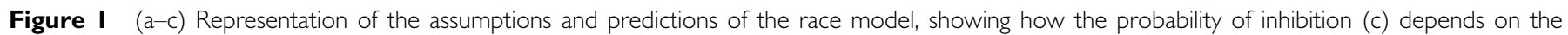
distribution of the go-task reaction times, stop-signal reaction time (SSRT), and stop-signal delay (SSD). (a) The probability of inhibition (white) and the

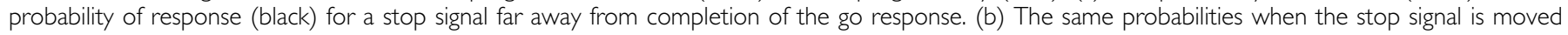
closer to completion of the go response, and shows how fewer responses can be inhibited. (d-h) The stop task operant paradigm. A nose-poke in the

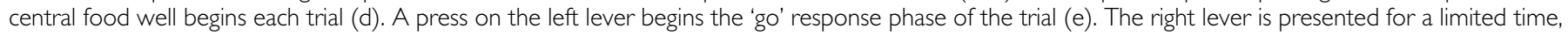
the limited hold, to promote rapid response. A right lever press ( $f$ ) is rewarded ( $g$ ). On 'stop' trials, during the response phase of the trial (e), a tone is played.

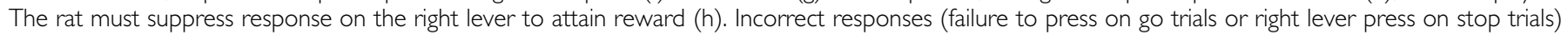
result in a timeout period.

both stop and go trials with a fixed LH. Training was completed for all rats at session 35) before the experimental protocol began.

Experiment 1. Before lesion-one set of stop-signal delays (SSDs) to generate inhibition functions and calculate SSRT. Rats first completed three no-delay sessions to calculate mean GoRT for each individual. SSDs for each rat were relative to its own mean GoRT, which controlled for individual differences in GoRT. The inhibition function was measured over five sessions with SSDs presented in pseudo-randomized order (from the set GoRT-600 ms, GoRT-500 ms, GoRT-400 ms, GoRT-300 ms, GoRT-200 ms), with one SSD per session. Rats were lesioned, given 7 days recovery time post-surgery, then retrained to a stable baseline level of performance and retested with one experimental set of SSDs to produce an inhibition function and calculate SSRT.

Experiment 2. For selected points on the stop-trial inhibition function, rats were treated with D-amphetamine sulfate $(0.3$ and $1.0 \mathrm{mg} / \mathrm{kg}$ expressed in terms of the salt, dissolved in saline to form a solution of 0.3 or $1.0 \mathrm{mg} / \mathrm{ml}$ and injected intraperitoneally as $1.0 \mathrm{ml} / \mathrm{kg}$ ) or saline vehicle.
These doses previously produced marked effects on the stop-signal task (Eagle and Robbins, 2003a). Drugs were presented as follows, where $\mathrm{B}=$ baseline (no-delay), $\mathrm{D}=$ drug $(0,0.3$ or $1.0 \mathrm{mg} / \mathrm{kg}$ - presented in balanced Latin-square design), $\mathrm{O}=$ day off (no testing - rats remained in home cages).

$\mathrm{B}-\mathrm{D}($ First dose - no delay for calculation of GoRT $)-\mathrm{O}-$

$\mathrm{B}-\mathrm{D}$ (First dose-GoRT-500 ms $)-\mathrm{O}-$

$\mathrm{B}-\mathrm{D}$ (First dose-GoRT-200 ms $)-\mathrm{O}-$

$\mathrm{B}-\mathrm{D}($ Second dose - no delay $)-\mathrm{O}-$

$\mathrm{B}-\mathrm{D}($ Second dose-GoRT-500 ms $)-\mathrm{O}-$

$\mathrm{B}-\mathrm{D}($ Second dose-GoRT-200 ms $)-\mathrm{O}-$

$\mathrm{B}-\mathrm{D}($ Third dose - no delay $)-\mathrm{O}-$

$\mathrm{B}-\mathrm{D}$ (Third dose-GoRT-500 ms $)-\mathrm{O}-$

$\mathrm{B}-\mathrm{D}($ Third dose-GoRT-200 ms $)-\mathrm{O}-$

Rats received intraperitoneal injections of drug or saline 20 min before the start of the test session and the session was completed within $40 \mathrm{~min}$ of drug/saline administration.

Experiment 3. Extended LH test. Following drug testing, rats received 3 no-delay sessions to check stability of performance before the extended $\mathrm{LH}$ test. All rats then received one session with a normal $\mathrm{LH}(\mathrm{LH} \times 1)$ and on the next day one session where the LH period on the stop trial 
was doubled $(\mathrm{LH} \times 2)$. This tested the ability to 'wait' or withhold pressing the right lever for the duration of the LH period. During the extended LH test, stop-signal trials were always presented with no delay, ie the stop signal occurred immediately after the left lever press at the beginning of the go trial. Performance at $\mathrm{LH} \times 2$ was then stabilized over a further 4 days, after which rats were given one pair of extended LH $\times 2$ sessions with $0.3 \mathrm{mg} / \mathrm{kg}$ D-amphetamine or saline vehicle, presented within a balanced Latin-square design.

\section{Spontaneous Locomotor Activity}

Spontaneous locomotor activity was measured between experiments 2 and 3 using 16 computerized photocell beam activity cages $(25 \times 40 \times 18 \mathrm{~cm})$ with two photocell beams dividing the length of the cage into three equal parts. Each photocell beam was positioned $1 \mathrm{~cm}$ above the floor of the cage. The number of beam breaks was recorded over a 120min period, separated into 5-min time bins, using an Acorn computer (Acorn Computers Ltd, Cambridge, UK). Cage allocation was randomized across experimental groups.

\section{Surgery}

Sham $(n=12)$ and Lesion $(n=12)$ groups were matched on pre-surgery task performance. All rats were treated $30 \mathrm{~min}$ before the start of surgery with $15 \mathrm{mg} / \mathrm{kg}$ desipramine $\mathrm{HCl}$ (Sigma Chemical Co., UK), dissolved in double-distilled water, to protect noradrenergic neurons from the neurotoxin. Rats were anesthetized with Avertin (10 g 99\% 2,2,2tribromoethanol (Sigma-Aldrich, Poole, UK) in $5 \mathrm{~g}$ tertiary amyl alcohol, diluted in a solution of $40 \mathrm{ml}$ ethanol and $450 \mathrm{ml}$ PBS), administered intraperitoneally as $1.0 \mathrm{ml} / 100 \mathrm{~g}$ rat, to induce anesthesia, and then as 1.0-ml intraperitoneal injections to maintain anesthesia.

Rats were secured in a stereotaxic frame fitted with atraumatic earbars, and received bilateral intracerebroventricular (i.c.v.) infusions of $80 \mu \mathrm{g}$ (free base) 5,7-dihydroxytryptamine (5,7-DHT) creatinine sulfate (Sigma Chemical Co.), dissolved in $10 \mu \mathrm{l}$ of $0.1 \%$ ascorbic acid in saline, whereas the shams received bilateral i.c.v. infusions of $10 \mu \mathrm{l}$ vehicle. Infusions were made bilaterally at coordinates AP
$-0.9 \mathrm{~mm}$ from bregma, $\mathrm{L} \pm 1.5 \mathrm{~mm}$ from the midline, and DV $-3.5 \mathrm{~mm}$ from dura, calculated from a stereotaxic atlas (Paxinos and Watson, 1986). The incisor bar was set at $-3.3 \mathrm{~mm}$ relative to the interaural line to give a flat skull position. Following each 8-min infusion, the injector was left in place for $2 \mathrm{~min}$ before withdrawal, to allow diffusion of the toxin/vehicle. Following surgery, animals were given free access to food for 5 days before behavioral testing to allow for the degeneration of serotonergic neurons (Bjorkland et al, 1975).

\section{Statistical Analysis}

Behavioral data were subjected to analysis of variance using a general linear model with significance at $\alpha=0.05$, using full-factorial models. Homogeneity of variance was verified using Levene's test. For repeated-measures analyses, Mauchly's test of sphericity was applied and the degrees of freedom corrected to more conservative values using the Huynh-Feldt epsilon for any terms involving factors in which the sphericity assumption was violated. Corrected degrees of freedom are shown to the nearest integer. Following repeated-measures analyses, simple one-way ANOVA or paired $t$-tests were used to investigate withinsubjects and between-subjects factors, with $\alpha$-adjusted using Sidak's method (Howell, 1997). $P$-values greater than 0.1 are reported as nonsignificant (NS). All figures show group means with error bars of \pm 1 SEM.

\section{Ex Vivo Lesion Analysis}

After completion of behavioral testing, rats were killed through exposure to increasing concentrations of carbon dioxide. The brains were rapidly removed and frozen on dry ice. Coronal sections were cut $(150 \mu \mathrm{m}$ thickness $)$ on a cryostat $\left(-10^{\circ} \mathrm{C}\right)$ from the frontal pole to the hippocampus and mounted onto pre-chilled microscope slides. A stainless-steel micro-punch $(0.75 \mathrm{~mm}$ diameter $)$ and a razor blade were used to remove $0.4-2.0 \mathrm{mg}$ aliquots of tissue from the following (left and right) brain regions on frozen slides: medial prefrontal cortex, dorsolateral and medial striatum, nucleus accumbens and hippocampus. Aliquots were weighed and samples homogenized in $100 \mu \mathrm{l}$ of $0.2 \mathrm{M}$

Table I Tissue Concentrations of 5-HT, DA and NA in Cortical, Striatal and Limbic Areas of i.c.v. 5,7-DHT-Lesioned and Sham-Operated Rats

\begin{tabular}{|c|c|c|c|c|c|c|}
\hline \multirow{2}{*}{ Region } & \multicolumn{2}{|c|}{$5-\mathrm{HT}$} & \multicolumn{2}{|c|}{ DA } & \multicolumn{2}{|c|}{ NA } \\
\hline & Sham & Lesion & Sham & Lesion & Sham & Lesion \\
\hline DMStr & $0.27(0.02)$ & $0.01 *(0.01)$ & $17.59(1.14)$ & $22.98(3.83)$ & $0.04(0.01)$ & $0.26(0.11)$ \\
\hline DLStr & $0.45(0.08)$ & $0.01 *(0.01)$ & | $4.72(1.75)$ & $12.68(1.42)$ & $0.13(0.04)$ & $0.17(0.04)$ \\
\hline
\end{tabular}

* $p<0.00$ I, significant differences between sham and lesion groups.

DA, dopamine; DLStr, dorsolateral striatum; DMStr, dorsomedial striatum; HPC, hippocampus; 5-HT, central serotonin; mPFC, medial prefrontal cortex; NA, noradrenaline; NAcb, nucleus accumbens.

The data are average levels ( \pm SEM) expressed as picomoles per milligram to two decimal places. 
perchloric acid to precipitate protein material. Following centrifugation at 6000 r.p.m. for $20 \mathrm{~min}$ at $4^{\circ} \mathrm{C}, 25 \mu \mathrm{l}$ of supernatant was taken and placed into autoinjector microvials ready for analysis.

Levels of 5-HT, noradrenaline (NA), and dopamine (DA) were determined in brain samples by reversed-phase, high-performance liquid chromatography, as described previously (Matthews et al, 2001; Winstanley et al, 2004a).

\section{RESULTS}

\section{ICV Neurochemistry}

From the original 24 rats, 3 did not complete the study resulting in final group sizes of sham $=10$ and lesion $=11$. Postmortem analysis of monoamine concentrations throughout the forebrain revealed a profound reduction in 5 -HT levels of greater than $90 \%$ for all of the regions assayed, compared with sham-operated controls (Table 1, Group $\mathrm{F}(1,19)=115.56, p<0.001 ; \operatorname{mPFC} \mathrm{F}(1,19)=21.44$, DMStr $\quad \mathrm{F}(1,20)=176.12$, DLStr $\mathrm{F}(1,20)=29.70$, NAcb $\mathrm{F}(1,19)=36.21$, $\operatorname{HPC} \mathrm{F}(1,19)=37.5$, all $p<0.001)$. Levels of DA and NA were not significantly different between lesion and control groups (DA Group $\mathrm{F}(1,19)=0.31$, NS; NA Group $F(1,19)=3.84, p \leqslant 0.07)$. These data are comparable with previous reports of the effects of central 5-HT depletion (Harrison et al, 1999; Winstanley et al, 2003, 2004b).

\section{Preoperative Performance}

Rats performed the stop-signal task within the constraints of the race model. All rats had normal inhibition functions, (Figure 2a: $\operatorname{SSD} F(3,69)=12.11, p<0.001$ ) and delaydependent inhibition was independent of go-trial accuracy, which did not change significantly across stop-signal delays $(\mathrm{SSD}, \mathrm{F}(4,75)=0.32$, NS; SSD $\times$ Group $\mathrm{F}(4,75)=0.37, \mathrm{NS})$.

Before surgery, prospective lesion groups were matched by LH (mean \pm SEM: control $1.64 \pm 0.15$, 5 -HT depletion $1.64 \pm 0.09$; Group $F(1,19)=0.01$, NS), inhibition function $($ Group $\times$ SSD $\mathrm{F}(3,69)=0.86, \quad \mathrm{NS}), \quad$ SSRT (Group $\mathrm{F}(1,19)=0.55$, NS), go-trial reaction time (GoRT; Group $\mathrm{F}(1,19)=0.03$, NS), stop, and go trial accuracy (in the 'nodelay' condition where the stop signal was presented at the start of the go trial (stop: Group $F(1,18)=0.03$, NS; go: Group $\mathrm{F}(1,19)=0.62, \mathrm{NS}))$, and LH (Group $\mathrm{F}(1,19)=0.01$, NS).

\section{Postoperative Performance}

There were no overall effects of 5-HT depletion on any aspect of baseline stop-signal task performance (Table 2). 5-HT depletion did not affect reacquisition of baseline (nodelay) levels of stop or go accuracy over 10 days (stop, Group F $(1,19)=2.29$, NS, Group $\times$ Day F $(8,165)=0.91$, NS; go, Group $\mathrm{F}(1,19)=0.01$, NS, Group $\times$ Day $\mathrm{F}(4,74)=0.49$, NS). Stop-trial accuracy was slightly reduced in the 5-HTdepleted group immediately following surgery but this was not statistically significant (3-day bins Group $\times$ Bin $\mathrm{F}(2,46)=0.684$, NS; no post hoc analyses significant). All rats showed normal inhibition functions (Figure 2b: SSD $\mathrm{F}(4,71)=21.00, p<0.001)$, with no difference between control and 5 -HT-depleted rat groups $($ SSD $\times$ Group $\mathrm{F}(4,71)=0.75$, NS).

5-HT depletion did not affect SSRT (Figure 2c: Post-surgery, Group $F(1,19)=0.60$, NS; Pre-post $\times$ Group $F(1,19)=1.99$, NS). There was no effect of pre-surgical baseline SSRT performance on the effect of 5-HT depletion on SSRT (high- and low-SSRT groups by median split of ranked presurgical performance, baseline SSRT $\mathrm{F}(1,18)=18.77$, $p<0.001$; baseline SSRT $\times$ Group $\times$ Pre-post $\mathrm{F}(1,18)=0.02$, NS; pre-surgery baseline SSRT $\times$ Group $\mathrm{F}(1,18)=2.26$, NS; post-surgery baseline SSRT $\times$ Group $=.522$, NS). 5 -HT depletion had no significant effect on GoRT (Group $\mathrm{F}(1,18)=0.85$, NS; Pre-post $\times$ Group $F(1,19)=2.79$ NS), no-delay go-trial accuracy (Group $\mathrm{F}(1,19)=0.69$, NS; Pre-post $\times$ Group $\mathrm{F}(1,19)=0.10$, NS) or no-delay stop trial accuracy (Group $\mathrm{F}(1,19)=1.05$, NS; Pre-post $\times$ Group F $(1,19)=1.74$, NS).

\section{Effects of D-Amphetamine}

Systemic D-amphetamine produced dose-dependent effects on GoRT and SSRT. D-Amphetamine decreased GoRT, following $0.3 \mathrm{mg} / \mathrm{kg}$ D-amphetamine, but GoRT was slightly (nonsignificantly) increased following $1.0 \mathrm{mg} / \mathrm{kg}$ D-amphetamine (Table 2: Dose $\mathrm{F}(1,22)=7.38, p<0.01$; saline $v s$ $0.3 \mathrm{mg} / \mathrm{kg}$, Dose $\mathrm{F}(1,17)=13.31, p<0.01$.; saline $v s 1.0 \mathrm{mg} /$ $\mathrm{kg}$, Dose $\mathrm{F}(1,17)=2.0, \mathrm{NS})$. D-Amphetamine also dose
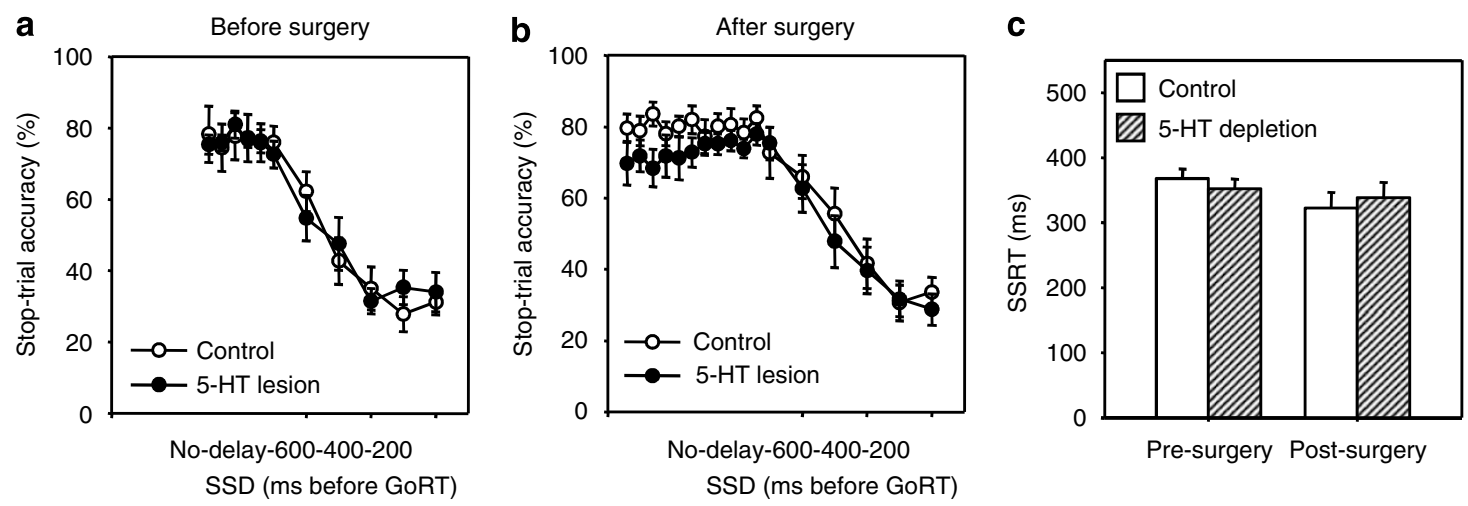

Figure 2 Performance on the stop-signal task. Inhibition functions for 5,7-DHT-lesion and control groups (a) before surgery and (b) after surgery. (c) SSRT before and after 5-HT depletion or sham surgery. Vertical bars represent \pm SEM. 
Table 2 Effects of 5-HT Depletion and D-Amphetamine Treatment on Stop-Signal Task Measures

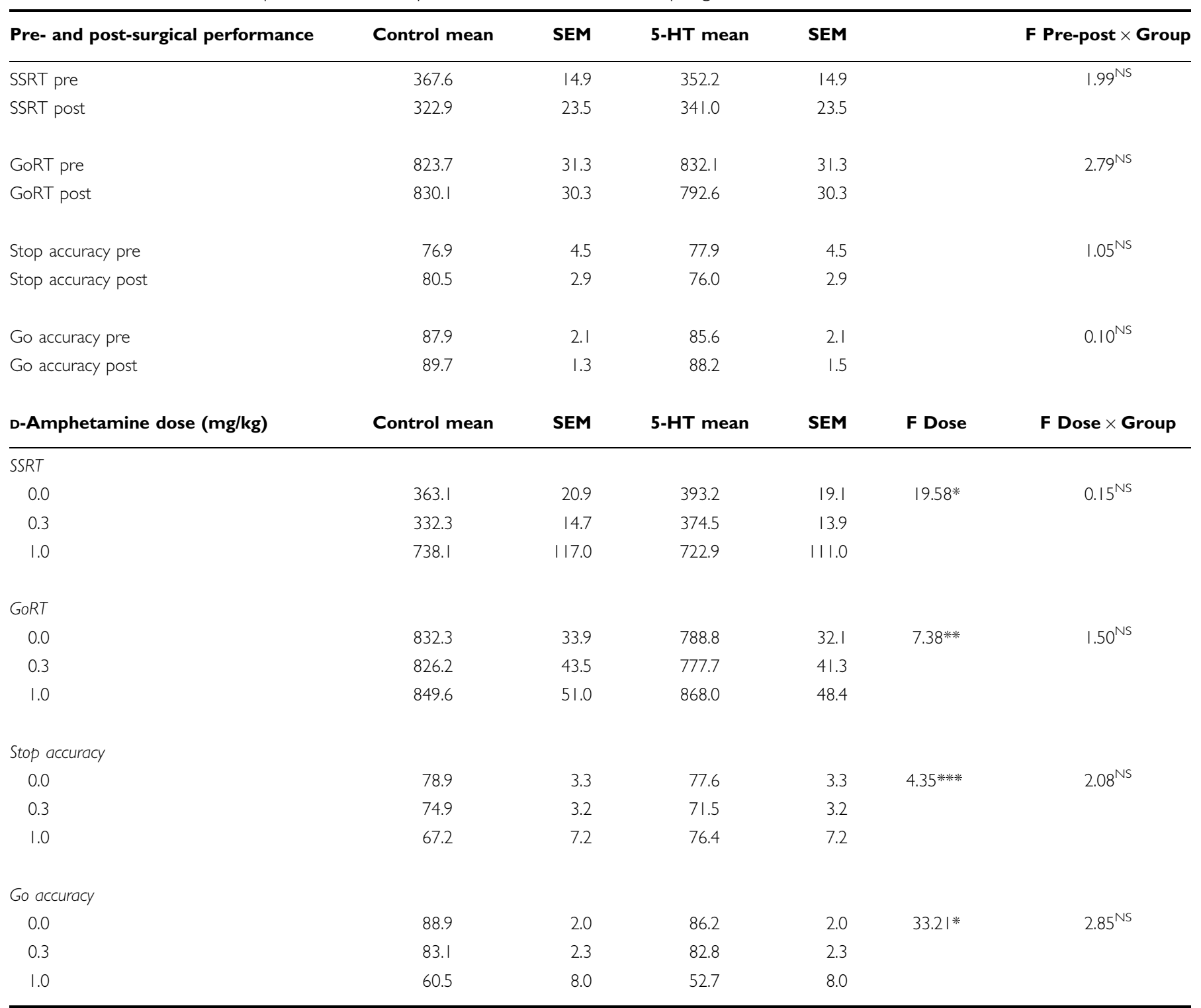

* $p<0.001, * * p<0.01$, **** $p<0.05$.

GoRT, go-trial reaction time; 5-HT, central serotonin; SEM, standard error of mean; SSRT, stop-signal reaction time; NS, not significant.

dependently affected SSRT (Table 2: Dose $\mathrm{F}(1,19)=19.58$, $p<0.001)$, with a large increase in SSRT following the high dose $(1.0 \mathrm{mg} / \mathrm{kg})$ of D-amphetamine. Although $0.3 \mathrm{mg} / \mathrm{kg}$ of D-amphetamine tended to decrease SSRT, this did not reach statistical significance (saline $v s \quad 0.3 \mathrm{mg} / \mathrm{kg}$, Dose $\mathrm{F}(1,17)=3.48, \quad p \leqslant 0.08 ; \quad$ saline $\quad$ s $\quad 1.0 \mathrm{mg} / \mathrm{kg}$, Dose $\mathrm{F}(1,17)=20.34, p<0.001)$.

No-delay stop-trial and go-trial accuracies were also significantly disrupted by D-amphetamine, particularly, by the highest dose, as observed in previous studies (Eagle and Robbins, 2003a): the extent of this impairment for the $1.0 \mathrm{mg} / \mathrm{kg}$ dose probably affected estimated SSRT at that dose. Go-trial accuracy was impaired by both doses of D-amphetamine, with effect size increasing with dose (Table 2, Dose $\mathrm{F}(1,25)=33.21, p<0.001$; saline $v s 0.3 \mathrm{mg} /$ $\mathrm{kg}$, Dose $\mathrm{F}(1,17)=5.92, p<0.026$; saline $v s 1.0 \mathrm{mg} / \mathrm{kg}$, Dose $\mathrm{F}(1,17)=43.22, p<0.001)$. Stop accuracy was also impaired by D-amphetamine (Table 2, Dose $\mathrm{F}(1,24)=4.35, p<0.05$; saline $v s 0.3 \mathrm{mg} / \mathrm{kg}$, Dose $\mathrm{F}(1,17)=9.34, p<0.01$; saline $v s$ $1.0 \mathrm{mg} / \mathrm{kg}$, Dose $\mathrm{F}(1,17)=5.55, p \leqslant 0.031)$.

Despite the clear effects of D-amphetamine on the stop task, there was no 5-HT-lesion-specific modulation of these effects on any measure of task performance: SSRT (Table 2: Group $\times$ Dose $F(1,19)=0.15$, NS); GoRT (Group $\times$ Dose $\mathrm{F}(2,29)=1.50$, NS), stop-trial accuracy (Group $\times$ Dose $\mathrm{F}(1,24)=2.08$, NS), or go-trial accuracy (Group $\times$ Dose $\mathrm{F}(1,24)=2.85, p \leqslant 0.09)$.

\section{Extended Limited Hold Test: Effects on Ability to Wait}

In contrast to the lack of effect on SSRT, rats with 5-HT depletion were significantly less able to withhold responding, or wait, during an extended LH test, whereas control rats were not impaired during performance of this test 
a

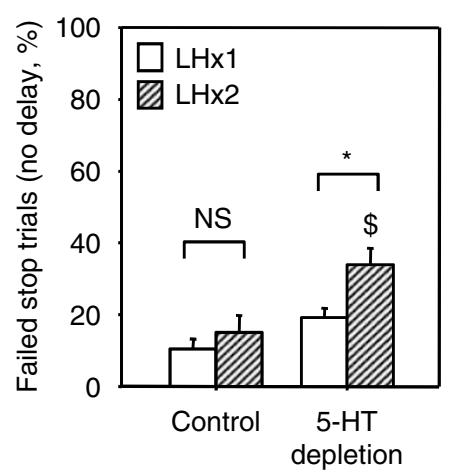

b

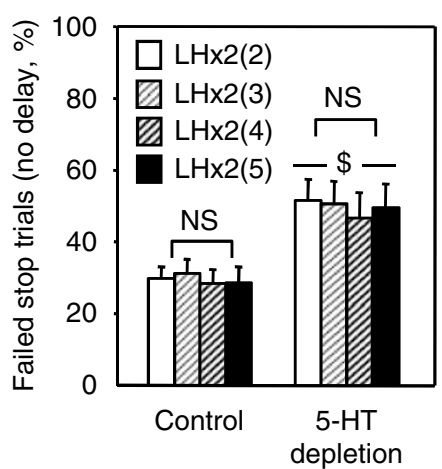

C

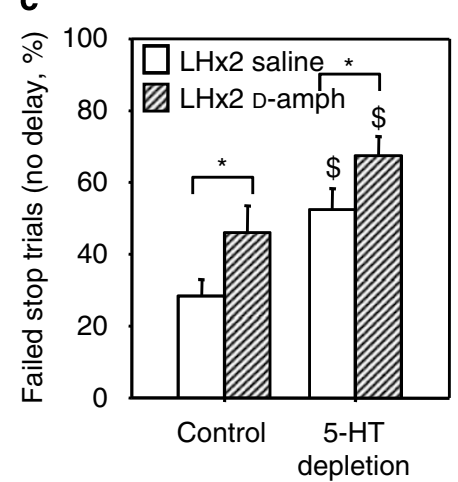

Figure 3 Extended limited hold test. (a) Effects of extended limited hold on SSRT. (b) Stabilized performance for sessions 2-5 at LH $\times 2$. (c) Effects of $0.3 \mathrm{mg} / \mathrm{kg}$ D-amphetamine on extended limited hold performance. Vertical bars represent $\pm \mathrm{SEM}$. *Represents significant difference between marked comparison. \$ represents significant difference between 5-HT depletion and control group. ( $\alpha$-adjusted from 0.05 using Sidak's method for multiple comparisons).

(Figure 3a: Group $\times$ LH F $(1,19)=4.64, p<0.05$; control LH $\mathrm{F}(1,9)=1.52$, NS; 5 -HT depletion LH $\mathrm{F}(1,10)=27.30$, $p<0.001)$. The 5-HT-depleted rats tended to be less able to withhold responding under normal $(\mathrm{LH} \times 1)$ conditions than control rats, although this did not reach statistical significance $(\mathrm{LH} \times 1$ Group $\mathrm{F}(1,21)=4.80, p \leqslant 0.05)$. However, under the extended $\mathrm{LH} \times 2$ condition, the 5-HTdepleted rats were significantly less able than control rats to withhold responding $(\mathrm{LH} \times 2$ Group $\mathrm{F}(1,21)=7.61$, $p \leqslant 0.01$ ).

There was no significant change in go-trial accuracy for either control or 5-HT-lesion group during the extended LH test $(\mathrm{LH} F(1,19)=0.23$, NS; Group $\times \mathrm{LH} F(1,19)=0.55$, $\mathrm{NS})$, but GoRT was significantly faster $(\operatorname{LH~} \mathrm{F}(1,19)=12.73$, $p<0.01)$. However, the control and 5-HT-depleted rats did not differ in the extent to which GoRT was speeded up during this test (Group $\times \operatorname{LH~} F(1,19)=0.01$, NS).

After the initial test, rat performance under the new test condition of $\mathrm{LH} \times 2$ was stabilized over a further four test sessions (Figure $3 \mathrm{~b}$ ). Although there was an increase in the number of failed trials between the first and second session of $\mathrm{LH} \times 2$ (comparison of hatched columns of Figure 3a with unfilled columns of Figure 3b: Day $F(1,19)=37.74$, $p<0.001)$, both groups were affected to the same degree $($ Day $\times$ Group $\mathrm{F}(1,19)=0.00$, NS), and the 5 -HT-depleted group was still significantly less able to withhold responding than the control group (Group $\mathrm{F}(1,19)=9.51, p<0.01$ ). This level of performance was stable for both groups across all four additional sessions of $\mathrm{LH} \times 2$ (Day $\mathrm{F}(2,43)=0.48$, NS; Day $\times$ Group F $(2,43)=0.22$, NS). Critically, the 5-HTdepleted group remained significantly less able to withhold responding than the control group (Group $\mathrm{F}(1,19=7.71$, $p \leqslant 0.01)$, suggesting this deficit was not simply a difference in behavioral flexibility in response to the change in task requirements.

Following $0.3 \mathrm{mg} / \mathrm{kg}$ D-amphetamine treatment in the LH $\times 2$ condition, all rats were significantly impaired at withholding responding (Figure 3c: Dose $\mathrm{F}(1,19)=9.53$, $p<0.01$; Dose $\times$ Group $F(1,19)=1.00$, NS). Further analysis showed that the amphetamine-induced waiting impairments were significant for both groups of rats (Control Dose $\mathrm{F}(1,9)=10.86, \quad p<0.01 ; \quad 5-\mathrm{HT} \quad$ depletion Dose $\mathrm{F}(1,10)=9.03, p \leqslant 0.013)$. The deficit in ability to wait during the extended LH period that was induced by the 5-
HT depletion was maintained for both vehicle and D-amphetamine treatment (saline Group $\mathrm{F}(1,20)=10.23$, $p<0.01 ; 0.3 \mathrm{mg} / \mathrm{kg}$ D-amphetamine Group $\mathrm{F}(1,20)=5.51$, $p \leqslant 0.03)$. There was no effect of $\mathrm{D}$-amphetamine on go-trial accuracy (Dose $\mathrm{F}(1,19)=1.51$, NS; Group $\times$ Dose $\mathrm{F}(1,19)=0.10$, NS), but GoRT was faster following D-amphetamine than saline (Dose $\mathrm{F}(1,19)=9.34, p<0.01$ ), with no differences between control and 5-HT-depleted rats in the extent to which GoRT was speeded up by D-amphetamine $($ Group $\times$ Dose $F(1,19)=0.77, \mathrm{NS})$.

\section{Spontaneous Locomotor Activity}

Rats with 5-HT depletion were more active than control subjects during the 120-min session (Figure 4: Group $\mathrm{F}(1,20)=12.50, p<0.01)$, in particular during the first 30 and final $30 \mathrm{~min}$ of the session (Group $\times$ Bin $\mathrm{F}(18,353)=2.21, p<0.01)$.

\section{DISCUSSION}

The main findings of this investigation indicate that generalized depletion of brain 5-HT disrupts certain aspects of impulsive action but not others. These findings have profound implications for any theory that 5-HT modulates a global construct of 'behavioral inhibition', and also challenge hypotheses put forward in recent reviews that postulate the clear compartmentalization of inhibitory deficits into 'impulsive action' vs 'impulsive choice'. This study is the first to directly dissociate two important forms of impulsive action that have previously been considered as directly comparable in terms of their neural basis.

Central 5-HT depletion did not affect SSRT, ie the speed of an inferred inhibitory process required to stop an already initiated action, and yet rats were severely impaired in a modified version of the same task that assessed the ability to withhold such responding, or 'wait'. 5-HT depletion did not significantly affect any aspect of go-trial performance in either the SSRT or waiting tests, confirming that the impairments induced by 5-HT depletion were specific to inhibition and not to activation of responding. Treatment with D-amphetamine further dissociated SSRT and 'waiting' impairments: although there were no lesion-specific effects 


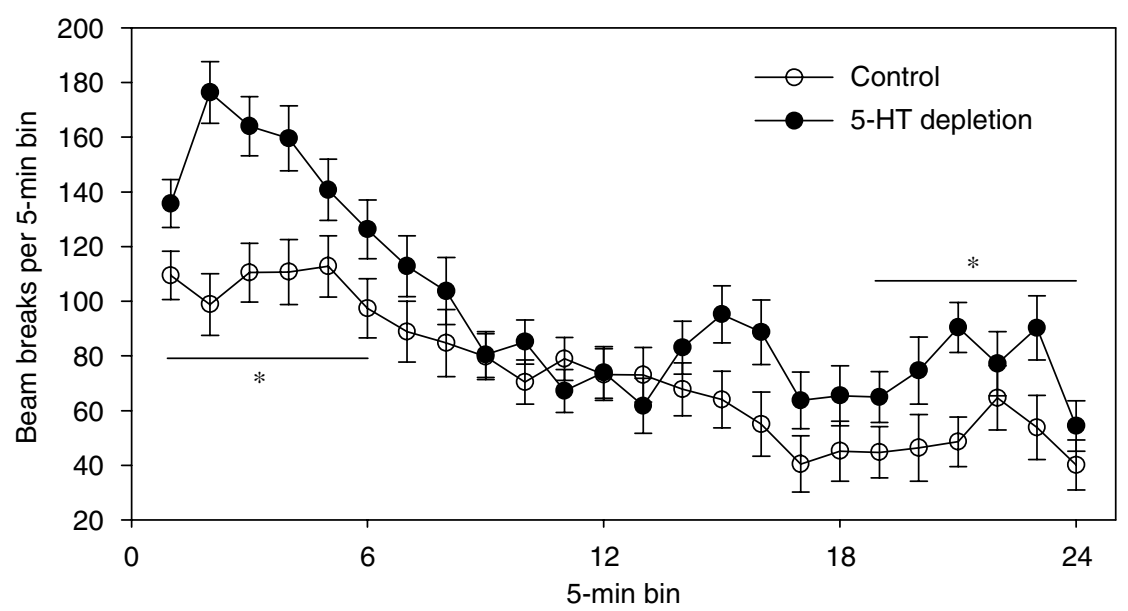

Figure 4 Spontaneous locomotor activity. Infrared beam breaks are shown for 5-min time bins over the 2-h session. Vertical bars represent \pm SEM. *Significant difference between control and 5-HT-depleted rats during a 30-min time bin ( $\alpha$-adjusted from 0.05 using Sidak's method for multiple comparisons).

of D-amphetamine, the dose that tended to decrease, or improve, SSRT $(0.3 \mathrm{mg} / \mathrm{kg})$ impaired waiting, and this was independent of 5-HT depletion.

The absence of SSRT deficits following 5-HT depletion was unlikely to have been the result of a failure to disrupt 5-HT transmission within the lesion group. 5-HT was significantly depleted in all sampled regions and there were profound behavioral effects on other aspects of the task. In addition to the 'waiting' deficit, 5-HT depletion increased locomotor activity in line with previous studies of spontaneous or conditioned locomotor activity (Gately et al, 1985; Williams et al, 1990; Winstanley et al, 2004a). Therefore, 5-HT depletion leads to hyperactivity and impaired inhibition of response selection, but not to any effect on canceling a response in action.

These findings are of great significance in the light of recent clinical studies in which 5-HT manipulations had no effect on SSRT, and our study confirms that 5-HT is not critical to the concept of impulsive action. For both rat and healthy human subjects, neither 5-HT depletion nor treatment with the SSRI citalopram significantly influenced SSRT, thus showing clear evidence of cross-species translation of these null effects (Chamberlain et al, 2006; Clark et al, 2005; Eagle et al, 2008).

The role of 5-HT in response inhibition might conceivably be critical to SSRT only if 'trial-by-trial performance was associated with motivational consequences in terms of either reinforcement or punishment' (Clark et al, 2005), as many 5-HT-modulated behaviors have a component of reward/punishment-related feedback. Indeed, clinical studies of SSRT usually have no formal reinforcement of correct trials, although more recent studies have begun to assess the role of performance feedback (eg Reynolds et al, 2008). However, our study showed that even in a foodreinforced stop-signal task there was no effect of 5-HT depletion on performance, and therefore, the failure to find effects of 5-HT depletion on SSRT in the clinical study was probably not because reinforcement was absent. It is more probable that 5-HT has little or no influence over SSRT.

The only evidence of a possible role for 5-HT in SSRT modulation comes from a clinical study of healthy volunteers with or without a family history of alcoholism
(Crean et al, 2002). The statistical significance of dietary tryptophan depletion in healthy volunteers with no family history of alcoholism was not reported but following tryptophan depletion their SSRTs were significantly lower than volunteers with a family history positive for alcoholism. Therefore, baseline impulsivity might have influenced the effectiveness of 5-HT depletion to disrupt SSRT. However, we found no evidence of baseline-dependent effects in our study: neither rats with high nor with low presurgical baseline SSRTs were susceptible to the effects of 5-HT depletion. Thus, in rats at least, baseline impulsivity did not influence the effects of 5-HT manipulations on SSRT.

In clear contrast to the lack of effect on SSRT, 5-HT depletion significantly impaired the ability to wait during an extended LH period on the stop-signal task. Such a difference in performance between the control and lesion groups on a brief, single-day test could potentially reflect altered behavioral flexibility, and thus a difference in the ability to respond to the changed task requirements. However, such a hypothesis would predict that both groups would stabilize to similar levels of performance. Clearly, this was not the case and the difference between groups in ability to withhold responding was stable across subsequent days of testing, suggesting that this impairment was indeed a robust 'waiting' impairment.

This form of impulse-control deficit most closely resembles the premature response deficit found in similar go/no-go tasks such as the 5-CSRT and DRL, both of which are markedly affected by manipulations of the 5-HT transmitter system. For example, 5-HT depletion (produced by either i.c.v. or intra-raphé 5,7-DHT infusion) profoundly and permanently increased premature responses in the 5-CSRT task (Carli and Samanin, 2000; Harrison et al, 1997; Winstanley et al, 2004a, b), and increased responding (decreased correctly completed trials) (Fletcher, 1995) and decreased inter-response times (Wogar et al, 1992) during DRL schedules. Recent studies have shown that although 5 -HT receptors are very strongly implicated in premature response control on the 5-CSRT task, the nature of this control over the ability to wait is complex, being both receptor-subtype- and site-dependent (Carli et al, 2006; Dalley et al, 2008; Passetti et al, 2003; Pattij and 
Vanderschuren, 2008; Robinson et al, 2007; Winstanley et al, 2004b, 2006).

Central 5-HT manipulations also affect the ability to wait for reinforcement following response in impulsive-choice paradigms, although the evidence is less clear cut than for tests in which responding itself must be withheld. Although some studies have found direct effects of 5-HT manipulations on impulsive choice (Bizot et al, 1999; Mobini et al, 2000a, b; Schweighofer et al, 2008; Wogar et al, 1993), others found no such effects (Crean et al, 2002; Tanaka et al, 2007; Winstanley et al, 2004a). This discrepancy has been attributed to subtle differences between tasks. However, a recent study showed that such differences in impulsive choice could also be 5-HT-receptor specific, as impulsive responding was decreased following treatment with the 5HT2 (C, B) receptor antagonist SER-082, but there were no effects of the 5-HT6 receptor antagonist SB-270146-A or the 5-HT2 (A, C) receptor antagonist, ketanserin on the same task (Talpos et al, 2006). Nevertheless, even in the nulleffect studies there is some evidence that 5-HT function may be indirectly relevant to impulsive choice control. For example, in a task where i.c.v. 5-HT depletion produced no significant effects on impulsive choice of a small, immediate reward over a larger, delayed reward, 5-HT depletion did attenuate the subsequent ability of $\mathrm{D}$-amphetamine to improve impulse control on this task (Winstanley et al, 2003). This implies that 5-HT may be relevant to 'waiting' deficits within both 'impulsive action' and 'impulsive choice' categories, and furthermore, that SSRT may stand alone as a distinct form of behavioral inhibition in terms of modulation, or lack thereof, by 5 -HT.

Central 5-HT depletion may disrupt 'waiting' because it impairs the ability to make accurate temporal judgments (Ho et al, 2002). For example, impaired performance on a DRL 20-s schedule following 5-HT depletion improved when the internal-timing aspect of the task was removed. Thus, when rats were provided with a light cue to signal reinforcer availability, 5-HT-depleted rats quickly acquired the task (Fletcher, 1995). Recent evidence from both human and rat studies confirm that specific 5-HT receptor subtypes may be involved in timing intervals of such magnitude (in the range of seconds to tens of seconds). For example, the 5-HT2A/1A receptor agonist psilocybin severely disrupted timing of intervals longer than $2-3 \mathrm{~s}$ in a range of tests with human subjects (Wittmann et al, 2007), and both 5-HT 1A and, 5-HT2A receptor manipulations disrupted temporal differentiation in rats (Asgari et al, 2006; Body et al, 2003). However, temporal differentiation on other tasks is not affected by 5-HT depletion (Chiang et al, 1999; Ho et al, 2002), suggesting that such a straightforward link between 5-HT and the timing of waiting periods is too simplistic. Nevertheless, the importance of 5-HT receptors in both premature response control and some forms of temporal differentiation suggests a potentially key role for 5 -HT in the accurate timing of extended waiting periods.

Relevant to the behavioral inhibition hypothesis, 5-HT depletion also impaired the ability to inhibit in go/no-go tasks, possibly because their ability to withhold responding was impaired (Harrison et al, 1999; Masaki et al, 2006). However, conventional go/no-go tasks also contain a decision-making component in selection-the go or no-go response, and 5-HT function is clearly implicated in aspects of decision-making across species on other tasks such as reversal learning (Clark et al, 2004, 2005; Ruotsalainen et al, 1997; Ward et al, 1999). Therefore, deficits in performance on go/no-go tasks following 5-HT manipulations may be a combination of impaired decision making and inability to withhold responding. In our study, the no-delay condition has many features in common with conventional go/no-go tasks, but the decision-making component of go vs no-go selection is absent as the go response should always be selected until a stop signal is superimposed upon it. 5-HT-depletion strongly impaired the ability to withhold responding when rats were required to wait for an extended period. This suggests that $5-\mathrm{HT}$ is important, not only for maintaining inhibition once a response has been stopped, but also for the initial selection of inhibition over response. However, the speed at which the inhibitory process occurs in the first instance is not influenced by 5 -HT mechanisms, in marked contrast with other data from both humans and rats showing significant effects of a selective NA-receptor blocker, atomoxetine, on SSRT (Chamberlain et al, 2006; Robinson et al, 2008).

The opposite effects of D-amphetamine on the two forms of impulsive action to decrease, or improve, SSRT while impairing the ability to wait, further emphasize the differences between these two forms of impulsive action. D-Amphetamine produced characteristic speeding effects on GoRT during both experiments but had opposite effects on the two measures of inhibition. The effects of D-amphetamine on waiting are consistent with its effects to impair premature responding on the 5-CSRT task (Harrison et al, 1997). This reinforces our hypothesis that 'waiting' and SSRT represent two different forms of inhibition that are differentially modulated in the brain.

This study challenges hypotheses put forward in recent reviews that postulate the compartmentalization of inhibitory deficits into 'impulsive action' $v s$ 'impulsive choice'. This is important because these categories of inhibition are fundamental to the definition of conditions such as ADHD. In clinical assessment, 'waiting' deficits are considered to be equivalent to impaired SSRTs as measures of impulsive action'. However, with regard to 5-HT function these two measures are clearly dissociable and therefore not directly interchangeable indicators of 'impulsive action'. Indeed, SSRT appears to stand alone as a measure of behavioral inhibition that is highly resistant to 5-HT perturbations. We conclude that the concept of behavioral inhibition as it stands is insufficiently precise to account for the effects of 5-HT on behavior, which has fundamental implications for the clinical assessment of inhibitory dysfunction in conditions such as ADHD.

\section{ACKNOWLEDGEMENTS}

This study was supported by a Wellcome Trust Programme Grant (076274/z/04/z) awarded to TWR, BJ Everitt, BJ Sahakian, and AC Roberts and completed within the University of Cambridge Behavioral and Clinical Neuroscience Institute, supported by a joint award from the Medical Research Council and the Wellcome Trust. OL was supported by a Marie Curie Fellowship. YP was supported by a predoctoral Formación Investigadora scholarship from Generalitat de Catalunya. 


\section{DISCLOSURE/CONFLICT OF INTEREST}

TWR discloses consultancy for Cambridge Cognition, Eli Lilly Inc., Wyeth, GlaxoSmithKline, and Allon Therapeutics, receives grant/research support from Pfizer, GlaxoSmithKline, and is a major stock shareholder in CeNeS, Cambridge Cognition, Allon Therapeutics. DME, OL, DEHT, YP, RZ, RG, and JWD have no disclosures.

\section{REFERENCES}

Aron AR, Poldrack RA (2005). The cognitive neuroscience of response inhibition: relevance for genetic research in attentiondeficit/hyperactivity disorder. Biol Psychiatry 57: 1285-1292.

Asgari K, Body S, Zhang Z, Fone KC, Bradshaw CM, Szabadi E (2006). Effects of 5-HT1A and 5-HT2A receptor stimulation on temporal differentiation performance in the fixed-interval peak procedure. Behav Processes 71: 250-257.

Bellgrove MA, Chambers CD, Vance A, Hall N, Karamitsios M, Bradshaw JL (2006). Lateralized deficit of response inhibition in early-onset schizophrenia. Psychol Med 36: 495-505.

Bizot J, Le Bihan C, Puech AJ, Hamon M, Thiebot M (1999). Serotonin and tolerance to delay of reward in rats. Psychopharmacology (Berl) 146: 400-412.

Bjorkland A, Baumgarten HD, Rensch A (1975). 5,7-Dihydroxytryptamine: improvement of its selectivity for serotonin neurons in the CNS by treatment with desipramine. J Neurochem 24: 833-835.

Body S, Kheramin S, Ho MY, Miranda F, Bradshaw CM, Szabadi E (2003). Effects of a 5-HT2 receptor agonist, DOI (2,5-dimethoxy4-iodoamphetamine), and antagonist, ketanserin, on the performance of rats on a free-operant timing schedule. Behav Pharmacol 14: 599-607.

Cardinal RN, Aitken MRF (2001). Whisker, version 2.2, computer software. http://www.whiskercontrol.com

Carli M, Baviera M, Invernizzi RW, Balducci C (2006). Dissociable contribution of 5-HT1A and 5-HT2A receptors in the medial prefrontal cortex to different aspects of executive control such as impulsivity and compulsive perseveration in rats. Neuropsychopharmacology 31: 757-767.

Carli M, Samanin R (2000). The 5-HT(1A) receptor agonist 8-OHDPAT reduces rats' accuracy of attentional performance and enhances impulsive responding in a five-choice serial reaction time task: role of presynaptic 5-HT(1A) receptors. Psychopharmacology (Berl) 149: 259-268.

Chamberlain SR, Blackwell AD, Fineberg NA, Robbins TW, Sahakian BJ (2005). The neuropsychology of obsessive compulsive disorder: the importance of failures in cognitive and behavioural inhibition as candidate endophenotypic markers. Neurosci Biobehav Rev 29: 399-419.

Chamberlain SR, Muller U, Blackwell AD, Clark L, Robbins TW, Sahakian BJ (2006). Neurochemical modulation of response inhibition and probabilistic learning in humans. Science 311: 861-863.

Chiang TJ, Al-Ruwaitea AS, Ho MY, Bradshaw CM, Szabadi E (1999). Effect of central 5-hydroxytryptamine depletion on performance in the free-operant psychophysical procedure: facilitation of switching, but no effect on temporal differentiation of responding. Psychopharmacology (Berl) 143: 166-173.

Clark L, Cools R, Robbins TW (2004). The neuropsychology of ventral prefrontal cortex: decision-making and reversal learning. Brain Cogn 55: 41-53.

Clark L, Roiser JP, Cools R, Rubinsztein DC, Sahakian BJ, Robbins TW (2005). Stop signal response inhibition is not modulated by tryptophan depletion or the serotonin transporter polymorphism in healthy volunteers: implications for the 5-HT theory of impulsivity. Psychopharmacology (Berl) 182: 570-578.
Clarke HF, Walker SC, Crofts HS, Dalley JW, Robbins TW, Roberts AC (2005). Prefrontal serotonin depletion affects reversal learning but not attentional set shifting. J Neurosci 25: 532-538.

Crean J, Richards JB, de Wit H (2002). Effect of tryptophan depletion on impulsive behavior in men with or without a family history of alcoholism. Behav Brain Res 136: 349-357.

Dalen L, Sonuga-Barke EJ, Hall M, Remington B (2004). Inhibitory deficits, delay aversion and preschool AD/HD: implications for the dual pathway model. Neural Plast 11: 1-11.

Dalley JW, Fryer TD, Brichard L, Robinson ES, Theobald DE, Laane $\mathrm{K}$ et al (2007). Nucleus accumbens D2/3 receptors predict trait impulsivity and cocaine reinforcement. Science 315: 1267-1270.

Dalley JW, Mar AC, Economidou D, Robbins TW (2008). Neurobehavioral mechanisms of impulsivity: fronto-striatal systems and functional neurochemistry. Pharmacol Biochem Behav 90: 250-260.

de Wit H, Crean J, Richards JB (2000). Effects of D-amphetamine and ethanol on a measure of behavioral inhibition in humans. Behav Neurosci 114: 830-837.

de Wit H, Enggasser JL, Richards JB (2002). Acute administration of D-amphetamine decreases impulsivity in healthy volunteers. Neuropsychopharmacology 27: 813-825.

Dougherty DM, Marsh DM, Mathias CW, Dawes MA, Bradley DM, Morgan CJ et al (2007). The effects of alcohol on laboratorymeasured impulsivity after L-tryptophan depletion or loading. Psychopharmacology (Berl) 193: 137-150.

Eagle DM, Bari A, Robbins TW (2008). The neuropsychopharmacology of action inhibition: cross-species translation of the stop-signal and go/no-go tasks. Psychopharmacology (Berl) 199: 439-456.

Eagle DM, Robbins TW (2003a). Inhibitory control in rats performing a stop-signal reaction-time task: effects of lesions of the medial striatum and D-amphetamine. Behav Neurosci 117: 1302-1317.

Eagle DM, Robbins TW (2003b). Lesions of the medial prefrontal cortex or nucleus accumbens core do not impair inhibitory control in rats performing a stop-signal reaction time task. Behav Brain Res 146: 131-144.

Evenden JL (1999). Varieties of impulsivity. Psychopharmacology 146: $348-361$.

Feola TW, de Wit H, Richards JB (2000). Effects of D-amphetamine and alcohol on a measure of behavioral inhibition in rats. Behav Neurosci 114: 838-848.

Fillmore MT, Rush CR (2002). Impaired inhibitory control of behavior in chronic cocaine users. Drug Alcohol Depend 66: 265-273.

Fletcher PJ (1995). Effects of combined or separate 5,7-dihydroxytryptamine lesions of the dorsal and median raphe nuclei on responding maintained by a DRL 20s schedule of food reinforcement. Brain Res 675: 45-54.

Gately PF, Poon SL, Segal DS, Geyer MA (1985). Depletion of brain serotonin by 5,7-dihydroxytryptamine alters the response to amphetamine and the havituation of locomotor activity in rats. Psychopharmacology (Berl) 87: 400-405.

Gauggel S, Rieger M, Feghoff TA (2004). Inhibition of ongoing responses in patients with Parkinson's disease. J Neurol Neurosurg Psychiatry 75: 539-544.

Harrison AA, Everitt BJ, Robbins TW (1997). Central 5-HT depletion enhances impulsive responding without affecting the accuracy of attentional performance: interactions with dopaminergic mechanisms. Psychopharmacology (Berl) 133: 329-342.

Harrison AA, Everitt BJ, Robbins TW (1999). Central serotonin depletion impairs both the acquisition and performance of a symmetrically reinforced go/no-go conditional visual discrimination. Behav Brain Res 100: 99-112.

Ho MY, Velazquez-Martinez DN, Bradshaw CM, Szabadi E (2002). 5-Hydroxytryptamine and interval timing behaviour. Pharmacol Biochem Behav 71: 773-785.

Howell DC (1997). Statistical Methods for Psychology, 4th edn. Duxbury Press: Belmont, CA. 
Linnoila M, Virkkunen M, Scheinin M, Nuutila A, Rimon R, Goodwin FK (1983). Low cerebrospinal fluid 5-hydroxyindoleacetic acid concentration differentiates impulsive from nonimpulsive violent behavior. Life Sci 33: 2609-2614.

Logan GD, Cowan WB (1984). On the ability to inhibit thought and action - a theory of an act of control. Psychol Rev 91: 295-327.

Masaki D, Yokoyama C, Kinoshita S, Tsuchida H, Nakatomi Y, Yoshimoto K et al (2006). Relationship between limbic and cortical 5-HT neurotransmission and acquisition and reversal learning in a go/no-go task in rats. Psychopharmacology (Berl) 189: 249-258.

Matthews K, Dalley JW, Matthews C, Tsai TH, Robbins TW (2001). Periodic maternal separation of neonatal rats produces regionand gender-specific effects on biogenic amine content in postmortem adult brain. Synapse 40: 1-10.

Mobini S, Chiang TJ, Al-Ruwaitea AS, Ho MY, Bradshaw CM, Szabadi E (2000a). Effect of central 5-hydroxytryptamine depletion on inter-temporal choice: a quantitative analysis. Psychopharmacology (Berl) 149: 313-318.

Mobini S, Chiang TJ, Ho MY, Bradshaw CM, Szabadi E (2000b). Effects of central 5-hydroxytryptamine depletion on sensitivity to delayed and probabilistic reinforcement. Psychopharmacology (Berl) 152: 390-397.

Monterosso JR, Aron AR, Cordova X, Xu J, London ED (2005). Deficits in response inhibition associated with chronic methamphetamine abuse. Drug Alcohol Depend 79: 273-277.

Oosterlaan J, Logan GD, Sergeant JA (1998). Response inhibition in $\mathrm{AD} / \mathrm{HD}, \mathrm{CD}$, comorbid $\mathrm{AD} / \mathrm{HD}+\mathrm{CD}$, anxious, and control children: a meta-analysis of studies with the stop task. J Child Psychol Psychiatry 39: 411-425.

Passetti F, Dalley JW, Robbins TW (2003). Double dissociation of serotonergic and dopaminergic mechanisms on attentional performance using a rodent five-choice reaction time task. Psychopharmacology (Berl) 165: 136-145.

Pattij T, Vanderschuren LJ (2008). The neuropharmacology of impulsive behaviour. Trends Pharmacol Sci 29: 192-199.

Paxinos G, Watson C (1986). The Rat Brain in Stereotaxic Coordinates, 2nd edn. Academic Press: New York.

Penades R, Catalan R, Rubia K, Andres S, Salamero M, Gasto C (2007). Impaired response inhibition in obsessive compulsive disorder. Eur Psychiatry 22: 404-410.

Reynolds B, Penfold RB, Patak M (2008). Dimensions of impulsive behavior in adolescents: laboratory behavioural assessments. Exp Clin Psychopharmacol 16: 124-131.

Robinson ES, Dalley JW, Theobald DE, Glennon JC, Pezze MA, Murphy ER et al (2007). Opposing roles for 5-HT(2A) and 5$\mathrm{HT}(2 \mathrm{C})$ receptors in the nucleus accumbens on inhibitory response control in the 5 -choice serial reaction time task. Neuropsychopharmacology 33: 2398-2406.

Robinson ES, Eagle DM, Mar AC, Bari A, Banerjee G, Jiang X et al (2008). Similar effects of the selective noradrenaline reuptake inhibitor atomoxetine on three distinct forms of impulsivity in the rat. Neuropsychopharmacology 33: 1028-1037.

Rubia K, Smith A, Taylor E (2007). Performance of children with attention deficit hyperactivity disorder (ADHD) on a test battery of impulsiveness. Child Neuropsychol 13: 276-304.

Ruotsalainen S, MacDonald E, Miettinen R, Puumala T, Riekkinen Sr P, Sirvio J (1997). Additive deficits in the choice accuracy of rats in the delayed non-matching to position task after cholinolytics and serotonergic lesions are non-mnemonic in nature. Psychopharmacology (Berl) 130: 303-312.

Schachar R, Tannock R, Marriott M, Logan G (1995). Deficient inhibitory control in attention deficit hyperactivity disorder. J Abnorm Child Psychol 23: 411-437.
Schweighofer N, Bertin M, Shishida K, Okamoto Y, Tanaka SC, Yamawaki $S$ et al (2008). Low-serotonin levels increase delayed reward discounting in humans. J Neurosci 28: 4528-4532.

Sonuga-Barke EJ (2003). The dual pathway model of AD/HD: an elaboration of neuro-developmental characteristics. Neurosci Biobehav Rev 27: 593-604.

Soubrié P (1986). Reconciling the role of central serotonin neurons in human and animal behavior. Behav Brain Sci 9: 319-364.

Talpos JC, Wilkinson LS, Robbins TW (2006). A comparison of multiple 5-HT receptors in two tasks measuring impulsivity. J Psychopharmacol 20: 47-58.

Tanaka SC, Schweighofer N, Asahi S, Shishida K, Okamoto Y, Yamawaki S et al (2007). Serotonin differentially regulates shortand long-term prediction of rewards in the ventral and dorsal striatum. PLoS ONE 2: e1333.

van den Wildenberg WP, van Boxtel GJ, van der Molen MW, Bosch DA, Speelman JD, Brunia CH (2006). Stimulation of the subthalamic region facilitates the selection and inhibition of motor responses in Parkinson's disease. J Cogn Neurosci 18: 626-636.

Walderhaug E, Landro NI, Magnusson A (2008). A synergic effect between lowered serotonin and novel situations on impulsivity measured by CPT. J Clin Exp Neuropsychol 30(2): 204-211.

Walderhaug E, Lunde H, Nordvik JE, Landro NI, Refsum H, Magnusson A (2002). Lowering of serotonin by rapid tryptophan depletion increases impulsiveness in normal individuals. Psychopharmacology (Berl) 164: 385-391.

Ward BO, Wilkinson LS, Robbins TW, Everitt BJ (1999). Forebrain serotonin depletion facilitates the acquisition and performance of a conditional visual discrimination task in rats. Behav Brain Res 100: 51-65.

Williams JH, Meara JR, Azmitia EC (1990). Effects of 5,7-dihydroxytryptamine injections in the fornix-fimbria on locomotor activity in photocell cages and the open field. Behav Brain Res 40: 37-44.

Winstanley CA, Dalley JW, Theobald DE, Robbins TW (2003). Global 5-HT depletion attenuates the ability of amphetamine to decrease impulsive choice on a delay-discounting task in rats. Psychopharmacology (Berl) 170: 320-331.

Winstanley CA, Dalley JW, Theobald DE, Robbins TW (2004a). Fractionating impulsivity: contrasting effects of central 5-HT depletion on different measures of impulsive behavior. Neuropsychopharmacology 29: 1331-1343.

Winstanley CA, Eagle DM, Robbins TW (2006). Behavioral models of impulsivity in relation to ADHD: translation between clinical and preclinical studies. Clin Psychol Rev 26: 379-395.

Winstanley CA, Theobald DE, Dalley JW, Glennon JC, Robbins TW (2004b). 5-HT2A and 5-HT2C receptor antagonists have opposing effects on a measure of impulsivity: interactions with global 5-HT depletion. Psychopharmacology (Berl) 176: 376-385.

Wittmann M, Carter O, Hasler F, Cahn BR, Grimberg U, Spring P et al (2007). Effects of psilocybin on time perception and temporal control of behaviour in humans. J Psychopharmacol 21: 50-64.

Wogar MA, Bradshaw CM, Szabadi E (1992). Impaired acquisition of temporal differentiation performance following lesions of the ascending 5-hydroxytryptaminergic pathways. Psychopharmacology (Berl) 107: 373-378.

Wogar MA, Bradshaw CM, Szabadi E (1993). Effect of lesions of the ascending 5-hydroxytryptaminergic pathways on choice between delayed reinforcers. Psychopharmacology (Berl) 111: 239-243.

Zepf FD, Holtmann M, Stadler C, Demisch L, Schmitt M, Wockel L et al (2008). Diminished serotonergic functioning in hostile children with ADHD: tryptophan depletion increases behavioural inhibition. Pharmacopsychiatry 41: 60-65.

Supplementary Information accompanies the paper on the Neuropsychopharmacology website (http://www.nature.com/npp) 